\title{
Constraint induced movement therapy for children with spastic hemiparesis cerebral palsy and mental disorder: report of a case study
}

Marcela Fischer de Almeida ${ }^{1 *}$, Andréa Obrecht ${ }^{2}$, Tatiana Jaworski de Sá Riechi ${ }^{3}$, Marise Bueno Zonta ${ }^{4}$ and Ana Crysthina Crippa ${ }^{5}$

*Correspondence: marcela.fischer.almeida@gmail.com

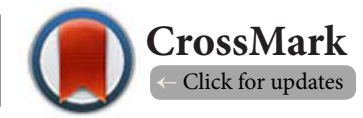

'Physiotherapist of the Clinics Hospital of the Federal University of Paraná (UFPR), Brazil.

${ }^{2}$ Physiotherapist of the Clinics Hospital of the Federal University of Paraná (UFPR), Curitiba, PR, Brazil.

${ }^{3}$ Psychologist, Professor in the Psychology Departamento f the Federal University of Paraná (UFPR), Curitba, PR, Brazil.

${ }^{4}$ Physiotherapist in the Neuropediatrics Center of the Clinics Hospital of the Federal University of Paraná (UFPR), Curitiba, PR, Brazil.

${ }^{5}$ Pediatric Neurologist, Adjunct Professor in the Pediatric Department of the Federal University of Paraná (UFPR), Curitiba, PR, Brazil.

\begin{abstract}
Introduction: Protocol for intensive Constraint-Induced Movement Therapy (CIMT) is designed to reduce problems related to the asymmetry of the upper limbs of children with Cerebral Palsy.

Objective: To describe how CIMT can be administered to two children with Hemiparetic Spastic Cerebral Palsy (HSCP) and Mental Disorder, discuss the strategies set out for coping with unsuitable behavior.

Materials and Methods: Two children with PC, (age, 11 and 14), with Oppositional Defiant Disorder and Autistic Spectrum Disorder respectively, performed to CIMT.

Results: Two children completed the CIMT and showed an improvement in the quantity, quality, and spontaneity of the use of the affected upper limb with the results being maintained for a month afterward.

Conclusion: This report shows the positive effects of CIMT for children with HSCP with Mental Disorder. Involvement of their families and the preparation of the therapist were decisive factors in making the intervention effective.
\end{abstract}

Keywords: Cerebral Palsy, Children, Treatment, Intellectual disability, Neurodevelopment

\section{Introdution}

Cerebral Palsy (CP) which is the most common cause of physical disabilities in children, can be accompanied by sensory, perceptive, and cognitive disturbances with regard to communication and behaviour [1]. The most common type of CP is Spastic Hemiparesis with a prevalence of 1/1300 live births [2]. According to the authors Basu et al. (2015), many daily activities require the hands to perform different movements at the same time in a coordinated way [2]. Approximately a half of the children with Spastic Hemiparesis (SH) experience problems in their ability to carry out everyday tasks and are restricted in their involvement in social and leisure activities, owing to upper limb functional limitations [2]. In addition, many of the children prefer not to use the affected upper limb, even if it entails a lower degree of difficulty [3].
The Constraint-Induced Movement Therapy (CIMT) is regarded as a widely effective method for improving several arm and hand functions of children with SH. Its treatment involves intensive practices aimed at the most affected limb with restrictions imposed on the other limb, forcing the children to find solutions to their movement problems [4]. The fact that this strategy is intensive and requires concentration and discipline, in the study by Chen et al (2014), to apply this protocol it is necessary that the child has adequate cognitive and coopering during assessments [5].

Mental disorders in childhood such as Autistic Spectrum Disorder (ASD) and Oppositional Defiant Disorder (ODD) are accompanied by behavioral problems [6]. Individuals with CP are at a heightened risk for mental health disorders because of the physical risk factors and variety of social with prevalence 
Almeida et al, Physical Therapy and Rehabilitation 2019,

http://www.hoajonline.com/journals/pdf/2055-2386-6-10.pdf

doi: $10.7243 / 2055-2386-6-10$

rates up to $57 \%$ [7].The impaired social interaction and communication skills and restricted and repetitive interests and behavior unusual responses to the sensory sensitivities that are observed in children with ASD, make the administering of CIMT a real challenge. In the same way, angry, negative, defiant, disobedient and hostile behavior aimed at figures of authority, as observed in ODD can undermine the physiotherapeutic measures being taken when the protocol is employed [8]. According to a recent study, many forms of psychopathology involve disruptions in cognitive functioning. These encompass attention, memory, language processing, and executive functions which can influence the administering of CIMT [8]. Human intelligence is characterized by a capacity to learn from experience and adapt to one's surroundings [9]. Intelligent children achieve a better performance in mental processes that involve cognitive functions for problem-solving, decision-making and reasoning $[\mathbf{9 , 1 0}]$. The child in Case 1 had practiced physiotherapy and swimming. The child in Case 2 has only practiced swimming. In both cases, the CIMT had not been administered before. The purpose of this study is to describe how the CIMT was administered for two children with Spastic Hemiparesis and Mental Disorder which cause unsuitable behavior, by taking account of their cognitive skills and the adaptations recommended for a successful intervention.

\section{Methods}

We are concerned with reporting an experimental type of case study that was carried out in three stages. Phase 1 involved making an initial assessment and employed the Teenager Upper Extremity Motor Activity Log (TMAL) and Pediatric Arm Function (PAFT) $[11,12]$. The degree of frequency and quality of the daily use of the most badly affected upper limb were evaluated by the TMAL through structured interviews for children and teenagers aged between 9 and 14 . The questionnaire comprised 22 tasks that were suitable for this age range [11]. PAFT is a behavioral observation method that contains information related to undertaking unilateral tasks (17 items) and bilateral tasks ( 8 items), and these were carried out by the badly affected upper limb [12]. This test is designed to trigger several patterns of movements of the impaired upper extremity by means of a wide range of ludic situations. The aim is to analyze the performance of several tasks carried out both unilaterally and bilaterally in a quantitative and qualitative way. The test must be administered twice. During the first session, the child must be discouraged from using the impaired upper limb. The spontaneous movement of each of the arms was observed. In the second session, a check was made of the tasks in which the child did not use the impaired upper limb and then was instructed to use it. This request can be made three times by means of touch. If no success is made through the previous interventions, the physiotherapist restricts the use of the impaired upper limb. This test consists of 26 tasks, 17 of which are unilateral and 9 bilateral. The score ranges as follows: a) zero - not used; b) one - very poor; c) two - poor; d) three-fair or moderate; e) four - almost normal; f) five - normal [12].

Independent mobility was also measured by means of the Motor Assessment Scale for the Upper Limb and the active and passive extension- flexion movements of the fist were measured by means of the rigid scales of a goniometer [13]. The spasticity was measured by the Modified Ashworth Scale [14]. The functional level was assessed using the Gross Motor Function Classification System (GMFCS) and the gross motor function score using the Gross Motor Function Measure, GMFM) $[15,16]$.

The spasticity was measured by the Modified Ashworth Scale. This scale is one of the most used clinical scale in measuring the increase of muscle tone which is manifested by an increased resistance of joints to passive movement [17]. In this study, the main muscles of the affected upper limb were measured: thumb adductor, flexion of the fingers, pronators, carpal flexion, and elbow flexion. The Modified Ashworth Scale was described as follows: during two repetitions of a passive motion within one second, resistance was measured on the following 6 point scale [18]: $0=$ no increased resistance; $1=$ slightly increased (catch followed by relaxation or minimal resistance at the end of the range of motion); $2=$ slightly increased resistance (catch followed by minimal resistance throughout less than half of the range of motion); $3=$ clear resistance throughout most of the range of motion; $4=$ Strong resistance, passive movement is difficult; $5=$ rigid flexion or extension. The total score is 25 . According to the authors TRENTINI et al. (2014), the Wechsler Abbreviated Scale of Intelligence (WASI) was employed for the initial neuropsychological evaluation; this assessed the cognitive functions and showed evidence of validity and reliability. This instrument consists of four subtests: Vocabulary, Block Design, Similarities, and Matrix Reasoning, which when grouped and examined, gave the Intelligence Quotient (generally, in verbal and execution terms) [17].

Phase 2 involved making an intervention with the CIMT which was carried out by the author and a qualified physiotherapist at the Neuropediatric Center of the Complex of Brazilian Companies of Hospital Services (EBSERH) the Hospital de Clínicas at Universidade Federal do Paraná (CENEP- UFPR), during the afternoon. The treatment involved three hours of intensive training every day over a period of 15 days. Following the CIMT protocol, these children received the same amount of therapy as children without Mental Disorders. Plaster cast was prepared the day before the first time the protocol was administered. They were tailor-made from the armpits to the fingers and reinforced with protective padding and cushions to relieve the pressure in the bony prominences. The thumb was kept in palmar abduction and the elbow at an angle of $90^{\circ}[11,18]$. The unaffected upper limb was restricted for a period of 13 days, during which time activities were carried out that were aimed at developing the affected upper limb. These activities were based on shaping. Taub et. al. (2011) described the shaping as a procedure whereby the subject is required to 
improve performance, usually in small steps, at each iteration of a movement in order to obtain the reward (enthusiastic praise, encouraging exclamations, and other signs of approval by the therapist) [19].

According to the study of Morris et al. (2006), in this approach a motor or behavioral objetive is approched in small steps by "sucessive aproximations": for example, the task canbe more difficult in accordance with a participant's motor capabilities, or the requirement for speed of performance can be progressively increased. Each functional activity is practiced for a set of ten 30- trials and expliciti feedbak is provided regarding the participant's performance during each trial [20]. The tasks were chosen on the basis TMAL and carried out with ludic materials suited to the age of the patient. On the 14th and 15th day, bimanual tasks were set without the use of the plaster cast. During the administration of the protocol, guidance was given about the kind of training exercises that could be done at home.

Phase 3 was the final evaluation of the CIMT Protocol which made use of TMAL and PAFT. The assessments were carried out by the same professional who applied the CIMT. This study was initiated after this project was approved by the Research Ethics Committee of Hospital de Clínicas of EBSERH- UFPR.

\section{Inclusion criteria}

The children who were diagnosed with Cerebral Palsy Spastic Hemiparesis (CPSH), were monitored at the CENEP. Before the patients were eligible for the protocol, they had to show an active motion with a minimum of shoulder flexion or abduction of $45^{\circ}, 20^{\circ}$ of elbow extension, $10^{\circ}$ of extension of the fist and at least two fingers and $10^{\circ}$ of abduction or extension of the thumb in the most affected limb (Grade IV of active movement) [21]. Children were included who were able to respond to simple orders and understand the setactivities.

\section{Exclusion criteria}

Children treated with botulinum toxin for a period of six months

\section{Case Description}

Case 1 was a male child, 11 years old, with right-sided and left lateralized hemiparesis, (GMFCS Level I), diagnosed with ODD, as monitored by CENEP. Certain rules were laid down to reduce the influence of ODD when the CIMT was administered, and these were decided together with the father who remained outside the room and could be called to the treatment room if his child refused to cooperate. From the first day of the treatment, the participant behaved in a way that was aggressive, disobedient and defiant. Despite this, the physiotherapist was prepared to overlook the negative actions, and showed patience; he was confident the aims of the treatment could be achieved while requesting the father to intervene whenever necessary. On the 10th day, the participant remained defiant and threatened the physiotherapist for a period of three hours. Comments like:"I am not going to do it !", "you can not order me about !", as well as constant verbal abuse, was always followed by the observation that it "was just a joke". There was one moment when the participant threatened to attack the physiotherapist with the plaster cast of the upper limb. The father was summoned and on that day it was necessary to refer the child to the Outpatients Pediatric Psychiatric Ward of the Hospital de Clínicas of UFPR so that there could be a particular intervention appropriate for ODD, without the need for the use of any medication. On the 14th and 15th days of treatment, the angry/defiant behavior was again very striking, perhaps on account of the stress caused by the protocol itself and it was necessary to summon the father to the treatment room again so that the participant's treatment could be brought to an end. Ludic activities such as games and amusing pastimes that could arouse the interest of theparticipant were prepared so that the therapist could complete the protocol. If the participant carried out the activities in a lively and timely way, at the end of the therapy session, he was allowed to choose an activity that he particularly liked. Positive reinforcement was another strategy that was employed when the participant cooperated with the set tasks and behaved in a suitable and respectfulmanner.

Case 2 was a male child, 14 years old, with left-sided and right-lateralized hemiparesis, (GMFCS Level I), diagnosed with light Autistic Spectrum Disorder through Aspergers Syndrome (DSM-5), and monitored by the CENEP. The difficulties with social relations were reduced by the active involvement of the family. During the treatment procedure, the mother remained in the waitingroom at the CENEP. The father who suggested that the child's dominant upper limb should be in plaster and remain so during the period of the Protocol shared the same difficulties in his attempts to encourage the child to undergo thetreatment. Both the father and the participant had difficulty in carrying out everyday tasks such as using cutlery for eating, the mouse for the computer and putting on/taking off their shoes. The challenges faced by the physiotherapist were related to the interests of the participant, as well as his repeated questions and anxieties. They also concerned the timetable, weather forecasts, (fear of rainfall and storms), the times when his mother would come to pick him up, and an interest in looking at and handling the cell phone. Another key challenge was caused by social barriers where the participant failed to enter into a conversation, hardly ever looked at the physiotherapist and when questioned about a particular subject only answered yes or no. However, the physiotherapist managed to attract the interest of the participant who was cooperative during the treatment in so far as none of the suggested activities that could be carried out were rejected. The different approaches adopted by the physiotherapist were as follows: giving guidance on how the participant could carry out the requested tasks at the moment when his attention was distracted and he was about to begin his repetitive behavior, the preparation of a wide range of different tasks to encourage him to become 
interested in the treatment, and patience in understanding his social limitations. The support of the family at home was of great value when undertaking this treatment, since it was at that time that the family encouraged the participant to persist with the functional changes provided by the method, in the best possible way (Figures 1-3).

The results of the functional assessment are in Table 1.

Both Case 1 and Case 2 showed Grade 4 of active motion and practiced swimming as one of the activities. Tables $\mathbf{2}$ and $\mathbf{3}$ display the clinical and neuropsychological assessment data.

\section{Discussion}

This report describes positive effects of a CIMT administered for three hours daily over a period of 15 days in two participants suffering from hemiparesis, Mental Disorder and with unsuitable behavior. The CIMT led to an improvement in the use of the upper limb involved in terms of quantity, quality, and spontaneity. Even though the participant's unsuitable behavior made it difficult to carry out an intensive treatment program, the way it was handled allowed us to conclude the protocol and led to a good outcome in both cases.

The increase in terms of both quantity and quality in the use of the affected upper limb was measured by TMAL. With regard to quantity, the use of the affected upper limb increased from rarely to normal in Case 1 and from very rarely to some times in Case 2. In the same way, the degree of quality (increased from fair or moderate to almost normal in both cases. After monitoring the post- application of the protocol, it was confirmed that there was no loss, or in other words, the quantity and quality were maintained at the same levels for each participant. The positive results obtained from TMAL corroborate the basic principles of the CIMT method, in which one of the main benefits was the change between the actual performance and its real potential for carrying out everyday activities since the objective of the method is to overcome the problem of the "non-use" that has been learnt. The everyday activities that require the use of the upper extremity and which help to overcome the problem of this "non-use" that has been learnt are linked to hygiene, nutrition, and clothing [22].In addition, CPSH affects motor pathways in the brain and also affects sensory pathways, which complicates the design of CIMT. However, the shaping can be considered a strategy to change this condition. Chorna et al. (2015) reported that shaping of movement through guide repetition during CIMT creates experience of successful movement essential to inferring more efficient actions and with that reverse the "learned non-use"

Table 1. Functional Assessment.

\begin{tabular}{llllll} 
& $\begin{array}{l}\text { TMAL } \\
\text { Pretreatment }\end{array}$ & $\begin{array}{l}\text { TMAL } \\
\text { After treatment }\end{array}$ & $\begin{array}{l}\text { TMAL } \\
\text { One month later }\end{array}$ & $\begin{array}{l}\text { PAFT } \\
\text { Pretreatment }\end{array}$ & $\begin{array}{l}\text { PAFT } \\
\text { After treatment }\end{array}$ \\
\hline Case 1 & $(1): 1.1$ & $(1): 3.5$ & $(1): 3.5$ & $(3): 2.9$ & $(3): 3.8$ \\
& $(2): 3$ & $(2): 4$ & $(2): 4$ & $(4): 2.8$ & $(4): 3.8$ \\
\hline Case 2 & $(1): 2.7$ & $(1): 5$ & $(1): 5$ & $(3): 3.5$ & $(3): 3.8$ \\
& $(2): 3.5$ & $(2): 4$ & $(2): 4$ & $(4): 3.6$ & $(4): 3.8$ \\
\hline
\end{tabular}

TMAL: Teenager Upper Extremity Motor Activity Log; PAFT: Pediatric Arm Function;

(1): How Often Scale; (2): How Well Scale; (3): Unilateral Section Score;

(4): Bilateral Section Score.

Table 2. Clinical assessment.

\begin{tabular}{lllll}
\hline & GMFM & $\begin{array}{l}\text { Motor Assessment } \\
\text { Scale of Upper Limb }\end{array}$ & $\begin{array}{l}\text { Modified Ashworth } \\
\text { Scale }\end{array}$ & Goniometer \\
\hline Case 1 & $94.2 \%$ & 11 & 14 & PFE:40 \\
& & & & AFE:10 \\
\hline Case 2 & $97.1 \%$ & 19 & 15 & PFE:60 \\
& & & & AFE:40 \\
\hline
\end{tabular}

GMFM: Gross Motor Function Measure; Motor Assessment Scale of Upper Limb; Goniometer: PFE: Passive Fist Extension; AFE: Active Fist Extension.

Table 3. Data from intelligence levels provided by wasy test.

\begin{tabular}{llllllllll}
\hline & QI Verbal & $\mathbf{P}$ & $\mathbf{C l}$ & IQ Execution & $\mathbf{P}$ & $\mathbf{C l}$ & IQ Total & $\mathbf{P}$ & $\mathbf{C l}$ \\
\hline Case 1 & 74 & 4 & Neighborin & 67 & 1 & Extremely low & 66 & 1 & Extremely l \\
Case 2 & 100 & 50 & Average g & 90 & 25 & Average & 94 & 34 & Average ow \\
\hline
\end{tabular}

QI Verbal: Quotient Score of Verbal Intelligence; P: Percentile; Cl: Classification; IQ Implementation: Intelligence Quotient Score; IQ: Intelligence Quotient Score (Total). 


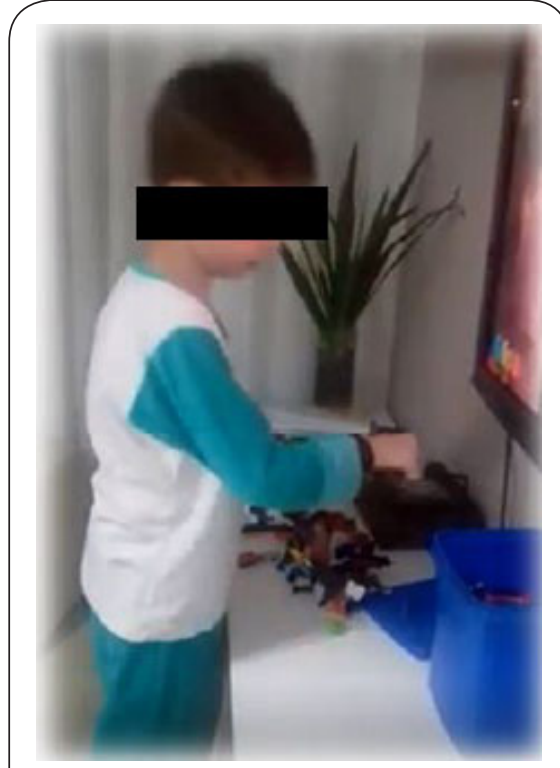

Figure 1. Activity: toys in the box Description: put the toys inside the box Target movement: grip and elbow extension.

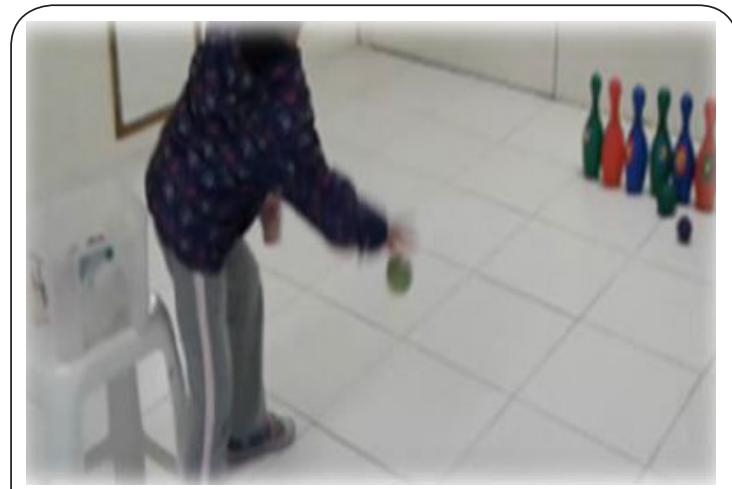

Figure 2. Activity: bowling Description: catch the ball and hit the bowling pins Target movement: spherical prehension, strength and motor coordination.

[23]. Some authors state that children with a CPSH disability have a limited voluntary motor system since the repetition of movements is an essential resource to improve the capacity of the brain to create new kinds of motor behaviour [22,23].

In administering PAFT, it was found that the use of the affected upper limb for unilateral and bilateral tasks remained fair function in Case 1 and increased from poor function to fair function in Case 2. PAFT is a scale for measuring ability and functionality and enables us to observe the capacity of children to carry out activities and tasks in an independent way with the impaired upper limb. In Case 1, there were changes related to the effectiveness and degree of acceptance of interventions made through CIMT, which help to change the performance

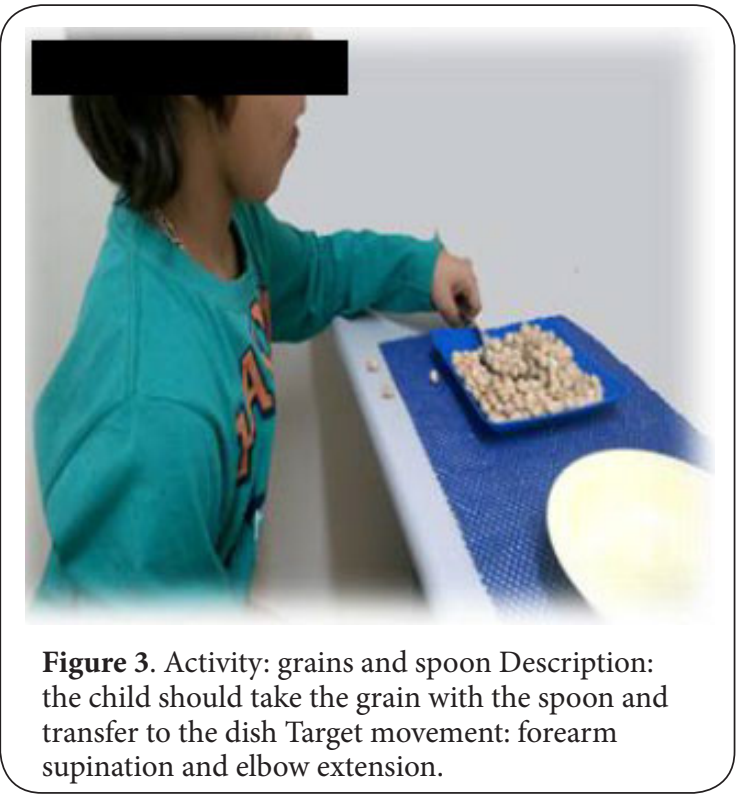

of the affected upper limb in everyday situations and social involvement [12]. In the systematic review about CIMT in children with SHCP without Mental Disorders, the authors found that CIMT had a beneficial effect and furthermore, this effect was beneficial in terms of both activity and participation, suggesting that the improved upper limb activity carried over into what the children actually did in real life with their upper limb [4].

The conclusion of the protocol, as well as the positive results observed in Case 1, are probably closely linked to the stance adopted by the physiotherapist, which is characterized by patience, persistence, and determination. According to the American Psychiatric Association (2013) [24], in ODD there is a recurring (and evolutionarily abnormal) pattern of irritated/ irritable, negative, defiant, disobedient and hostile attitudes aimed at figures of authority. During the protocol, the physiotherapist is this figure of authority who demands that a difficult activity should be carried out. This can be frustrating to the child and probably explains his mounting anger and threatening manner. The physiotherapist must be willing to disregard these negative feelings of the child and together with the parents, lay down rules, while at the same time being prepared to accept their implications [24]. The presence of the father in the room at the side and in the room itself when necessary is a means of managing the protocol.

Even when it has been decided only to call the father in the most extreme circumstances, the fact that he is nearby the whole time acts as a "constraint", something which is needed for this child. According to Ghosh et al. (2017) [25] parental practices are the most accessible and efficient aids when managing the alterations caused by ODD.

While the Protocol is being administered, the child is given the complete attention of the physiotherapist and is encouraged to tolerate the stress of having to work hard with his/her 
Almeida et al, Physical Therapy and Rehabilitation 2019,

http://www.hoajonline.com/journals/pdf/2055-2386-6-10.pdf

doi: $10.7243 / 2055-2386-6-10$

impaired limb. Complete attention and tolerance of stress are points suggested by Kersten et al., (2016) [26] to assist the behavior of children through ODD. Administering the CIMT for a child with ODD and reducing his frustration by providing better functional conditions, might be one of the ways that can enable health professionals to handle these children [27]. Even though it is not easy, the effect it has on the individual and its direct implications on academic performance will probably show the value of making this effort.

The positive results observed after CIMT in Case 2 underlined the effectiveness of involving the family during the treatment and this is supported by the study of An (2017) [27]. This author believes that parental training with work centered on the family for children with Autism Spectrum Disorder (ASD) can greatly enhance their treatment. The fact that the father was able and available to help constraint the dominant upper limb together with his son, acted as a stimulus by encouraging him to tolerate the treatment and thus reduce the difficulty of everyday tasks. By being aware of his difficulties, the participant had a similar understanding to that of his father and felt less frustrated. Moreover, once he had successfully completed the task, his manner was lively and he showed satisfaction. This awareness and sense of motivation made it easier to incorporate interventional procedures and provide an opportunity to achieve better results [27].

Throughout the protocol, it was expected that there would be an introspective behavior and little conversation with the physiotherapist owing to the nature of ASD and this illustrates the difficulty of overcoming the behavioral barrier. Cognitive impairment in social relationships, social-emotional agnosia, and difficulties in establishing relationships, are often observed in children with ASD [28-30]. This impairment can also be expressed in the form of anxiety, irritability, labile mood, inattention, hyperactivity and sleep problems [31]. These are alterations that can be known by the physiotherapist who is going to administer the CIMT because they will guide his conduct. The preparation of this physiotherapist and the involvement and encouragement of the family are of crucial importance in allowing children with ASD to be submitted to intensive protocols.

With regard to the cognitive function, the two children followed a pattern that is made clear in the literature. In the case of ASD, the literature states that $44 \%$ of the children have an average intellectual capacity, and in ODD, that they have low performance in intelligence tests. In this report, both achieved good results with CIMT $[8,32]$.

In the clinical practice of a physiotherapist who is trained in administering the CIMT Protocol, it is very likely that he/she will come to work with children with motor alterations linked to Mental Disorders, which is also a cause of their unsuitable behavior. On the basis of research studies which carried out a detailed assessment of the occurrence of $\mathrm{CP}$ and Mental Disorders, it was found that there was a greater prevalence among them (8.7\%) than among the general population [33]. This finding suggests that these professionals should know more about these disorders since there might be a significant increase of this problem in future generations [33]. The prevalence of ASD has increased considerably in recent decades and those affected represent about $1 \%$ of the world population [33]. Asperger Syndrome corresponds to $17 \%$ of the individuals with ASD and $0.5 \%$ of the children population [34]. In its turn, ODD is one of the most common Mental Disorders among children, with an estimated rate from 1 to $11 \%$ and is thought to be four to five times more common among young children [35]. AlthoughCIMT is only recommended for children with a suitable behavior, we noted that good results were obtained in these two children with CPSH and Mental Disorders.

Perhaps in some situations, eligibility for the protocol should not only depend on the behavior of the child, but also on the preparation of the physiotherapist and the ability of the family to cope with alterations in behavior.

Further studies involving a larger number of Mental Disorders patients are necessary to corroborate these findings. In conclusion, it might be feasible to administer CIMT to children with CPSH and Mental Disorders and achieve satisfactory results. Unsuitable behavior is a challenge to the physiotherapist who must be guided on how to manage each type of disorder. The strategies used by the physiotherapist while carrying out the protocol encouraged the children to become involved and cooperate and thus reduce their behavioral problems.

\section{Competing interests}

The authors declare that they have no competing interests.

Authors' contributions

\begin{tabular}{|l|c|c|c|c|c|}
\hline Authors' contributions & MFA & AO & TJR & MBZ & ACC \\
\hline Research concept and design & $\checkmark$ & $\checkmark$ & $\checkmark$ & $\checkmark$ & $\checkmark$ \\
\hline Collection and/or assembly of data & $\checkmark$ & $\checkmark$ & $\checkmark$ & $\checkmark$ & $\checkmark$ \\
\hline Data analysis and interpretation & $\checkmark$ & $\checkmark$ & $\checkmark$ & $\checkmark$ & $\checkmark$ \\
\hline Writing the article & $\checkmark$ & $\checkmark$ & $\checkmark$ & $\checkmark$ & $\checkmark$ \\
\hline Critical revision of the article & $\checkmark$ & $\checkmark$ & $\checkmark$ & $\checkmark$ & $\checkmark$ \\
\hline Final approval of article & $\checkmark$ & $\checkmark$ & $\checkmark$ & $\checkmark$ & $\checkmark$ \\
\hline Statistical analysis & $\checkmark$ & $\checkmark$ & $\checkmark$ & $\checkmark$ & $\checkmark$ \\
\hline
\end{tabular}

Acknowledgement

Acknowledgement for Neuropediatric Center of the Complex of Brazilian Companies of Hospital Services (EBSERH) the Hospital de Clínicas at Universidade Federal do Paraná (CENEP- UFPR).

\section{Publication history}

Editor: Mohammad H. Hadadzadeh, Wheeling Jesuit University, USA. Received: 16-June-2019 Final Revised: 23-July-2019

Accepted: 29-July-2019 Published: 01-Sep-2019

\section{References}

1. Rosenbaum P. Cerebral palsy: what parents and doctors want to know. BMJ. 2003; 326:970-4. | Article | PubMed Abstract | PubMed FullText

2. Basu AP, Pearse J, Kelly S, Wisher V and Kisler J. Early intervention to improve hand function in hemiplegic cerebral palsy. Front Neurol. 2014; 5:281. | Article | PubMed Abstract | PubMed FullText

3. Taub E, Griffin A, Uswatte G, Gammons K, Nick J and Law CR. Treatment 
Almeida et al, Physical Therapy and Rehabilitation 2019,

of congenital hemiparesis with pediatric constraint-induced movement therapy. J Child Neurol. 2011; 26:1163-73. | Article | PubMed Abstract | PubMed FullText

4. Chiu HC and Ada L. Constraint-induced movement therapy improves upper limb activity and participation in hemiplegic cerebral palsy: a systematic review. J Physiother. 2016; 62:130-7. | Article | PubMed

5. Chen $\mathrm{CL}$, Lin KC, Kang LJ, Wu CY, Chen HC and Hsieh YW. Potential predictors of functional outcomes after home-based constraint-induced therapy for children with cerebral palsy. Am J Occup Ther. 2014; 68:15966. | Article | PubMed

6. Xu M, Jiang W, Du Y, Li Y and Fan J. Executive Function Features in Drugnaive Children with Oppositional Defiant Disorder. Shanghai Arch Psychiatry. 2017; 29:228-236. | Article | PubMed Abstract | PubMed FullText

7. Whitney D, Warschausky S and Peterson M. Mental Health disorders and pysical risk factors in children with cerebral palsy: a cross-sectional study. Developmental Medicine \& Child Neurology. 2018; 1-7. | Article

8. Keyes KM, Platt J, Kaufman AS and McLaughlin KA. Association of Fluid Intelligence and Psychiatric Disorders in a Population-Representative Sample of US Adolescents. JAMA Psychiatry. 2017; 74:179-188. | Article | PubMed Abstract | PubMed FullText

9. Sternberg R and Sternberg K. Psicologia Cognitiva. Cencange Learning. 2016.

10. STERNBERG R. Psicologia Afetiva. Tradução Maria Regina Borges Osório. Porto Alegre: Artes Médicas. 2000.

11. GARCIA J, KNABBEN R and PEREIRA N, et al. Terapia por Contensão Induzida (TCI) em adolescentes com hemiparesia espástica: relato de caso. Fisioter. Mov. 2012; 25:895-906.

12. Uswatte G, Taub E, Griffin A, Rowe J, Vogtle L and Barman J. Pediatric Arm Function Test: reliability and validity for assessing more-affected arm motor capacity in children with cerebral palsy. Am J Phys Med Rehabil. 2012; 91:1060-9. | Article | PubMed Abstract | PubMed FullText

13. Graham HK, Aoki KR, Autti-Ramo I, Boyd RN, Delgado MR, Gaebler-Spira DJ, Gormley ME, Guyer BM, Heinen F, Holton AF, Matthews D, Molenaers G, Motta F, Garcia Ruiz PJ and Wissel J. Recommendations for the use of botulinum toxin type $A$ in the management of cerebral palsy. Gait Posture. 2000; 11:67-79. | Article | PubMed

14. SPOSITO M and RIBERTO M. Avaliação da funcionalidade da criança com paralisia cerebral espástica. Acta Fisiátrica. 2010; 17:50-61.

15. Palisano R, Rosenbaum P, Walter S, Russell D, Wood E and Galuppi B. Development and reliability of a system to classify gross motor function in children with cerebral palsy. Dev Med Child Neurol. 1997; 39:214-23. | Article | PubMed

16. RUSSELL D, ROSENBAUM P, WRIGHT M and AVERY L. Gross Motor Function Measure (GMFM-66 \& GMFM 88) User's Manual. 2nd edn. London: Mac Keith Press. 2013.

17. Meseguer-Henarejos AB, Sanchez-Meca J, Lopez-Pina JA and CarlesHernandez R. Inter- and intra-rater reliability of the Modified Ashworth Scale: a systematic review and meta-analysis. Eur J Phys Rehabil Med. 2018; 54:576-590. | Article | PubMed

18. Li F, Wu Y and Li X. Test-retest reliability and inter-rater reliability of the Modified Tardieu Scale and the Modified Ashworth Scale in hemiplegic patients with stroke. Eur J Phys Rehabil Med. 2014; 50:9-15. | Article | PubMed

19. Taub E, Griffin A, Uswatte G, Gammons K, Nick J and Law CR. Treatment of congenital hemiparesis with pediatric constraint-induced movement therapy. J Child Neurol. 2011; 26:1163-73. | Article | PubMed Abstract | PubMed FullText

20. Morris DM, Taub E and Mark VW. Constraint-induced movement therapy: characterizing the intervention protocol. Eura Medicophys. 2006; 42:257-68. | Article | PubMed

21. Winstein CJ, Miller JP, Blanton S, Taub E, Uswatte G, Morris D, Nichols $D$ and Wolf $S$. Methods for a multisite randomized trial to investigate the effect of constraint-induced movement therapy in improving upper extremity function among adults recovering from a cerebrovascular stroke. Neurorehabil Neural Repair. 2003; 17:137-52. | Article | PubMed
22. Ju Y and Yoon IJ. The effects of modified constraint-induced movement therapy and mirror therapy on upper extremity function and its influence on activities of daily living. J Phys Ther Sci. 2018; 30:77-81. | Article | PubMed Abstract | PubMed FullText

23. Chorna O, Heathcock J, Key A, Noritz G, Carey H, Hamm E, Nelin MA, Murray M, Needham A, Slaughter JC and Maitre NL. Early childhood constraint therapy for sensory/motor impairment in cerebral palsy: a randomised clinical trial protocol. BMJ Open. 2015; 5:e010212. | Article | PubMed Abstract | PubMed FullText

24. American Psychiatric Association. Diagnostic and statistical manual of disorders, Fifth Edition. 2013.

25. Ghosh A, Ray A and Basu A. Oppositional defiant disorder: current insight. Psychol Res Behav Manag. 2017; 10:353-367. | Article | PubMed Abstract | PubMed FullText

26. Kersten L, Pratzlich M, Mannstadt S, Ackermann K, Kohls G, Oldenhof H, Saure D, Krieger K, Herpertz-Dahlmann B, Popma A, Freitag CM, Trestman RL and Stadler C. START NOW - a comprehensive skills training programme for female adolescents with oppositional defiant and conduct disorders: study protocol for a cluster-randomised controlled trial. Trials. 2016; 17:568. | Article | PubMed Abstract | PubMed FullText

27. An SL. Parent Training Occupational Therapy Program for Parents of Children with Autism in Korea. Occup Ther Int. 2017; 2017:4741634. | Article | PubMed Abstract | PubMed FullText

28. GARCIA-SANCHEZ A, MORA E and SNACHEZ-LOPES C et al. Atencion temprana centrada en la família. Rev. Ciglo Cero. Revista Española sobre Discapacidad Intelectual. 2014; 45:6-27.

29. Gleason MM, Goldson E and Yogman MW. Addressing Early Childhood Emotional and Behavioral Problems. Pediatrics. 2016; 138. | Article | PubMed

30. Badescu GM, Filfan M, Sandu RE, Surugiu R, Ciobanu O and Popa-Wagner A. Molecular mechanisms underlying neurodevelopmental disorders, ADHD and autism. Rom J Morphol Embryol. 2016; 57:361-6. | Pdf | PubMed

31. MASKEY M, WARNELL F and PARR J et al. Emotinal and Behavioural problems in children with Autism Spectrum Disorder. J. Autism. Dev. Disord. 2013; 43:851-859.

32. Stepanova E, Dowling S, Phelps M and Findling RL. Pharmacotherapy of emotional and behavioral symptoms associated with autism spectrum disorder in children and adolescents. Dialogues Clin Neurosci. 2017; 19:395-402. | Article | PubMed Abstract | PubMed FullText

33. Delobel-Ayoub M, Klapouszczak D, van Bakel MME, Horridge K, Sigurdardottir S, Himmelmann K and Arnaud C. Prevalence and characteristics of autism spectrum disorders in children with cerebral palsy. Dev Med Child Neurol. 2017; 59:738-742. | Article | PubMed

34. OHAN J, ELLEFSON $S$ and CORRIGAN P. Brief report: The impacto $f$ chanching from DSM-IV “Asperger's' to DSM-5 'Autism Spectrum Disorder' diagnostic labels on stigma and treatment attitudes. J Autism Dev Disorder. 2015; 45:3384-3389.

35. Pisano S, Muratori P, Gorga C, Levantini V, Iuliano R, Catone G, Coppola $G$, Milone $A$ and Masi $G$. Conduct disorders and psychopathy in children and adolescents: aetiology, clinical presentation and treatment strategies of callous-unemotional traits. Ital J Pediatr. 2017; 43:84. I Article | PubMed Abstract | PubMed FullText

\section{Citation:}

de Almeida MF, Obrecht A, de Sá Riechi TJ, Zonta $\mathrm{MB}$ and Crippa AC. Constraint induced movement therapy for children with spastic hemiparesis cerebral palsy and mental disorder: report of a case study. Phys Ther Rehabil. 2019; 6:10. http://dx.doi.org/10.7243/2055-2386-6-10 